\title{
Biologia floral E ReProdutiva de CORCHORUS HIRTUS L. (Malvaceae) uma espécie de mata seca do Cerrado
}

\author{
Jane Gomes da Rocha Souza ${ }^{1}$,Viviany Teixeira do Nascimento ${ }^{1 *}$, Juliana de Meneses Ribas ${ }^{2}$.
}

${ }^{1}$ Universidade do Estado da Babia, Departamento de Ciências Humanas/Campus IX, Barreiras, Babia.

${ }^{2}$ Universidade Federal do Oeste da Babia, Campus Reitor Edgard Santos, Barreiras, Babia, Brasil.

*Autor para correspondência: viryteixeira@gmail.com

Recebido em 19 de novembro de 2017. Aceito em 23 de março de 2018. Publicado em 14 de abril de 2018.

Resumo - Corchorus hirtus L. é uma espécie da família Malvaceae da qual se tem pouco conhecimento dos seus aspectos reprodutivos. O objetivo deste trabalho foi descrever a biologia floral, o sistema reprodutivo e os polinizadores de C. hirtus encontrada em um fragmento de Mata Seca no Cerrado, na cidade de Barreiras, Bahia (Nordeste do Brasil). Foram descritas as características florais da espécie, os visitantes florais e realizados experimentos de polinização manual. C. hirtus possui flores amarelas, actinomorfas, pentâmeras e estames livres. Possui flores hermafroditas, mas algumas funcionalmente masculinas. As flores ofertam pólen por pouco tempo, porém a viabilidade polínica é alta. Três táxons de visitantes florais foram observados: uma espécie de Vespidae (não identificada), uma abelha (Megachile (Acentron) verrucosa) e um agente pilhador Pbibalosoma phyllinum. Houve alto índice de frutificação em polinização aberta, autopolinização manual e espontânea e uma baixa frutificação em experimentos de polinização cruzada. Os resultados das polinizações manuais sugerem que $C$. birtus é autocompatível reduzindo a dependência do serviço realizado pelos polinizadores para se reproduzir, o que representa uma característica vantajosa para espécie que é considerada colonizadora de novos ambientes.

Palavras-chave: Andromonoicla Funcional; Autocompatibilidade; Autopolinização Espontânea.

\section{Floral and Reproductive biology of Corchorus hirtus L. (Malvaceae) a SPECIES of DRY forest in the Cerrado}

Aвstract - Corchorus birtus is a species belonging to the Malvaceae family which little has been known about their reproductive aspects. The main purpose of this study was to describe C. birtus found in a fragment of dry forest in the Cerrado located in Barreiras, Bahia (Northeastern Brazil), considering its floral biology, the breeding systems and the pollinators. The floral characteristics and the flower visitors of this species were described, and then artificial pollination was performed. C. hirtus has yellow, actinomorphic and pentamerous flowers and free stamens. It has hermaphrodite flowers, but some male functionally. The flowers have pollen supply for a short time, though the pollen viability is high. Three taxa of floral visitors were observed: one Vespidae species (unidentified), a bee (Megacbile (Acentron) verrucosa) and a nectar scavenger Phibalosoma phyllinum. There was a high fruiting rate in open-pollination, artificial and spontaneous selfpollination; on the other hand the fruit set on cross-pollination experiments was low. The results from artificial pollination suggest that $C$. hirtus is self-compatible reducing its reliability on pollinators to reproduce, which is an advantageous characteristic for species that is considered colonizing new environments.

Keywords: Functional Andromonoecy; Self-Compatibility; Spontaneous Self-Pollination.

Biología floral y reproductiva de Corchorus hirtus L. (Malvaceae) una especie de bosque seco del Cerrado

Resumen - Corchorus hirtus L. es una especie de la familia Malvaceae de la cual se tiene poco conocimiento de sus aspectos reproductivos. El objetivo de este trabajo fue describir la biología floral, el sistema reproductivo y los polinizadores de $C$. 
hirtus encontrada en un fragmento de Bosque Seco en el Cerrado, en la ciudad de Barreiras, Bahía (Nordeste de Brasil). Fueron descriptas las características florales de la especie, los visitantes florales y realizados experimentos de polinización manual. C. birtus posee flores amarillas, actinomorfas, pentámeras y estambres libres. Posee flores hermafroditas, pero algunas funcionalmente masculinas. Las flores ofertan polen por poco tiempo, pero su viabilidad polínica es alta. Tres taxones de visitantes florales fueron observados: una especie de Vespidae (no identificada), una abeja (Megacbile (Acentron) verrucosa) y un agente usurpador Phibalosoma phyllinum. Hubo alto índice de fructificación en polinización abierta, autopolinización manual y espontánea y una baja fructificación en experimentos de polinización cruzada. Los resultados de las polinizaciones manuales sugieren que $C$. birtus es autocompatible reduciendo la dependencia del servicio realizado por los polinizadores para reproducirse, lo que representa una característica ventajosa para especie que es considerada colonizadora de nuevos ambientes.

Palabras clave: Andromonoicla Funcional; Autocompatibilidad; Autopolinización Espontánea.

\section{INTRODUÇÃO}

Aproximadamente $90 \%$ das espécies de plantas com flores são hermafroditas, com indivíduos produzindo flores bissexuais. O restante das espécies possui sistema sexual no qual os indivíduos produzem flores com um único sexo, ou possuem formas intermediárias em que flores unissexuais e bissexuais estão associadas num mesmo indivíduo ou em indivíduos diferentes da espécie (Barrett 2000).

Num mesmo indivíduo, a presença de flores pistiladas e hermafroditas caracteriza a ginomonoicia, e a presença de flores estaminadas e hermafroditas, a andromonoicia. Além disso, muitas plantas com flores morfologicamente hermafroditas podem apresentar gineceu ou androceu não funcionais que podem ser semelhantes aos órgãos férteis, em forma e tamanho. Nesses casos, a identificação do sexo floral é dificultada e necessita de estudos pertinentes (Vieira e Fonseca 2014). Esta perda da funcionalidade de um órgão pode ser resultado de mutações pontuais ou até mesmo de disponibilidade fisiológica (Oliveira e Maruyama 2015).

A adoção de um desses sistemas sexuais representa o "interesse" da planta em melhorar o fitness de um dos sexos. Enquanto a ginodioicia representa o investimento na produção de sementes a andromonoicia permite aumentar a quantidade de pólen e otimizar a função masculina sem os custos da produção de pistilos e sua presença entre as angiospermas é mais comum (Lloyd 1980).

Além da diversidade de sistemas sexuais, as plantas ao longo de sua evolução se adaptaram a diferentes formas de polinização. A polinização cruzada que envolve a transferência de pólen entre flores do mesmo indivíduo (geitonogamia) ou entre flores de indivíduos diferentes (xenogamia) e a autopolinização que envolve a fertilização a partir de junção de pólen e óvulo oriundos da mesma flor (Vieira e Fonseca 2014). A comparação entre as vantagens e desvantagens desses dois tipos de polinização é um tópico de discussão clássico dentro da biologia floral, mas não há dúvidas que a polinização cruzada produz descendentes com maior variabilidade genética. No entanto, a autopolinização pode ser uma estratégia útil quando condições ambientais são desfavoráveis, quando polinizadores estão ausentes ou em habitats extremos quando qualquer variabilidade pode modificar o arranjo de características genéticas que permite as plantas sobreviver naqueles ambientes (Lloyd e Schoen 1992; Oliveira e Maruyama 2015). Nesse sentido, o conhecimento da forma de reprodução das espécies é importante porque ela apresenta grande efeito na colonização de diferentes habitats e também na resposta das plantas às alterações ambientais.

Em algumas famílias de angiospermas a autopolinização é marcante. Em Malvaceae, por exemplo, 
apesar dos grupos mais basais serem alógamos e polinizados tanto por beija flores quanto por morcegos a migração dessa família para ambientes mais abertos favoreceu a polinização por abelhas e o desenvolvimento da autopolinização, que parece ser responsável pelo sucesso reprodutivo de muitas espécies da família (Gottsberger 1986).

O gênero Corchorus é um dos gêneros de Malvaceae para o qual a autopolinização é uma estratégia reprodutiva frequente (Sinha et al. 2011). Esse gênero de ervas e arbustos baixos possui entre 40 e 100 espécies, a maioria espontâneas que ocorrem em regiões tropicais e subtropicais do mundo (Kundu 1951; Purseglove 1968; Chang e Miau 1989). As espécies desse gênero são importantes componentes em áreas de regeneração nas florestas tropicais (Colmenero-Robles et al. 2010) e no Brasil são encontradas em estado natural (não cultivadas) 6 espécies, que ocorrem em quase todos os estados e tipos de vegetação, incluindo áreas antrópicas (Bovini 2015). Uma dessas espécies é $C$. hirtus uma planta herbácea comum em áreas degradadas e margem de estradas (Souza e Esteves 2002).

$\mathrm{Na}$ literatura não existem muitas informações sobre $C$. hirtus. A maior parte dos trabalhos refere-se a sua presença em levantamentos fitosociológicos, por exemplo, Guglieri-Caporal et al. (2010) que mencionaram a espécie em seu inventário sobre ervas daninhas em áreas de pasto no Cerrado Sul Mato-grossense, Gavilanes e D’ Angieri Filho (1991) que encontraram C. birtus em áreas ruderais dentro de perímetro urbano do município de Lavras, Santos et al. (2009) que observaram C. hirtus crescendo em áreas de pasto e cultivo em ambiente de Caatinga em Pernambuco, semelhante ao que ocorreu com Cuevas e Manzanares (1993) que registraram a ocorrência $C$. hirtus em levantamento sobre ervas daninhas do cultivo de cana de açúcar em Cuba. A ocorrência da espécie nessas áreas antropizadas é possivelmente favorecida pela facilidade que tem a mesma tem de estabelecer-se em solo raso (Sinha et al. 2011). Todavia, os estudos que envolvem a biologia reprodutiva, a biologia floral e os sistemas de polinização dessa espécie são inexistentes.

Diante disso, nos propusemos a estudar uma população de Corchorus hirtus em uma pequena área de mata seca no oeste da Bahia com os seguintes objetivos: 1- investigar a existência de dimorfismo nas flores e apontar como cada morfo contribui para o sucesso reprodutivo da espécie; 2 - investigar a dependência da espécie do serviço ofertado pelos polinizadores; 3- caracterizar o sistema reprodutivo adotado pela espécie.

\section{MATERial e MÉtodos}

Area de estudo

O trabalho de campo foi desenvolvido no município de Barreiras-Bahia, em uma área pertencente ao Campus Reitor Edgard Santos da Universidade Federal do Oeste da Bahia (UFOB), conhecido como Campus da Prainha, tendo como coordenadas geográficas centrais $12^{\circ} 08^{\prime} 58,8^{\prime \prime S}$ e 4500'20,6”W (Figura 1). No local estão presentes as fitofisionomias de Mata Seca e Mata Ciliar do bioma Cerrado (Ribeiro e Walter 2008).

O Campus está inserido em uma região de clima Tropical (Aw/Köppen-Geiger) (Peel 2007), com duas estações bem definidas, uma estação seca e fria (maio a setembro), e uma estação chuvosa e quente (outubro a abril). As temperaturas variam ao longo do ano entre $22^{\circ} \mathrm{C}$ e $27^{\circ} \mathrm{C}$ em média com intensa radiação solar e a precipitação varia de 800 milímetros a 1.600 (Batistella e Valadares 2009). Na região a vegetação predominante é o Cerrado, que corresponde a aproximadamente $57 \%$ da área total (Mendonça 2006). As principais fitofisionomias 
da região são o Cerrado sensu stricto, Mata Seca, Mata Ciliar, Mata de Galeria e Cerradão (Costa e Costa 2010).

Figura 1 - Campus da Universidade Federal Oeste da Bahia, Barreiras, Nordeste do Brasil. A- visão geral do Campus; Bárea de vegetação em que ocorreu o estudo.

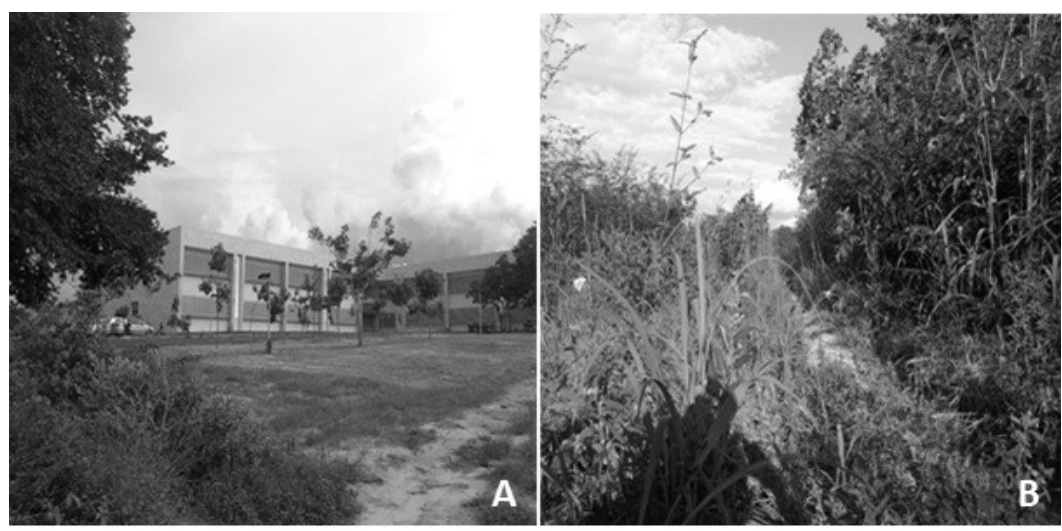

Para o estudo foram selecionados 13 indivíduos de Corchorus hirtus L. encontrados em uma área de mata seca dentro do Campus. Os experimentos foram realizados no pico de floração entre os meses de fevereiro e abril de 2014. Duas amostras dos indivíduos estudados foram coletadas, herborizadas (Mori et al. 1989) e depositadas no herbário BRBA da UFOB (BRBA, nº 5445, 5446).

\section{Morfometria floral}

Flores foram coletadas e conservadas em álcool a 70\% para análise em laboratório com auxílio de paquímetro manual e estereomicroscópio. Foram tomadas medidas do comprimento e largura das pétalas, sépalas, tamanho total pistilo, do ovário e do estigma. Para esta análise considerou-se 10 flores por morfotipo utilizando 10 indivíduos da população. As medidas foram comparadas utilizando-se o Teste de Tukey a 5\% de probabilidade no programa ASSISTAT 7.7.

\section{Biologia floral}

Flores de $C$. hirtus foram analisadas quanto ao horário e período da antese. Para tanto, diferentes flores em pré-antese foram ensacadas e observadas desde a abertura do botão floral até a senescência. Ao longo da antese registrou-se a coloração das flores, o período de receptividade estigmática e a viabilidade polínica, a presença de osmóforos, de pigmentos ultravioleta e de néctar. Os indivíduos também foram observados, de forma a contabilizar o número de flores abertas por indivíduo e por inflorescência.

A receptividade estigmática foi verificada em campo de hora em hora após a abertura da flor com emprego de peróxido de hidrogênio (Dafni 1992), bem como a disponibilidade do pólen por meio de um leve toque nas anteras. Essas análises foram realizadas em 10 flores por morfotipo utilizando 10 indivíduos da população. A viabilidade polínica (5 flores) foi verificada em microscópio com solução de carmim acético (Dafni 1992), havendo a contagem de 300 grãos de pólen por lâmina, num total de 1500 grãos de pólen analisados.

Para verificação da presença de pigmentos com absorção no espectro ultravioleta, as flores foram expostas 
a atmosfera de hidróxido de amônia, enquanto que para detecção de osmóforos em campo, as flores foram imersas durante cinco minutos em vermelho neutro. Para confirmação da localização dos odores, partes florais foram separadas e colocadas em recipientes fechados e depois de cinco minutos foi analisada sua mudança de coloração (Dafni 1992).

A presença/ausência de néctar foi verificada por meio da inserção de microcapilares de $5 \mu \mathrm{l}$ na flor (Kearns e Inouye 1993).

\section{Sistema reprodutivo}

Seguindo os métodos estabelecidos por Radford et al. (1974) foram realizados os testes de polinização manual com diferentes tratamentos: 1- polinização cruzada manual (entre morfotipos iguais (intramorfo) e diferentes (intermorfo); 2 - autopolinização manual (autogamia); 3 - autopolinização espontânea e 4 - apomixia. Além destes, um grupo controle foi utilizado, no qual observou-se a formação natural de frutos.

Para realização dos experimentos os botões em pré-ântese foram ensacados previamente e os tratamentos realizados quando a flor estava aberta com pólen disponível e estigma receptivo. Para os tratamentos da polinização cruzada e da apomixia as flores em pré-antese foram emasculadas para evitar a autopolinização espontânea, enquanto para o tratamento da autopolinização espontânea as flores foram ensacadas sem nenhum tratamento. Em cada tratamento utilizou-se 10 flores para cada tamanho de pistilo. Ao todo foram utilizadas 60 flores de pistilo longo e 60 flores de pistilo curto distribuídas nos 13 indivíduos da população.

Para as análises de morfometria floral, biologia floral (exceto viabilidade polínica onde $n=5$ ) e sistema reprodutivo foram utilizadas 10 flores por morfotipo escolhidas aleatoriamente entre os 13 indivíduos da população estudada. Este número foi estabelecido em razão do baixo número de indivíduos e flores disponíveis durante o período investigado.

\section{Visitantes florais}

As observações dos visitantes florais foram realizadas entre 14:00h e 18:00h (período que compreende a abertura do botão até a senescência da flor), em três dias não consecutivos na mesma semana, totalizando 12 horas de observação em dia ensolarado. O comportamento dos visitantes foi analisado através de observações focais diretas e registrado seu tempo de permanência na flor, as estruturas tocadas durante a visita e a frequência de visitação. Os visitantes foram fotografados, coletados, encaminhados para identificação e posteriormente depositados no Laboratório de Zoologia da UFOB.

\section{REsultados}

\section{Morfologia Floral}

Corchorus hirtus é uma espécie herbácea (Figura 2a), variando de 0,5 a 1 metro de altura. Apresenta folhas simples, alternas, de margem serreada, pilosas e pecioladas. Possui inflorescência axial e terminal apresentando de uma a quatro flores por inflorescência. As flores são actinomorfas, pedunculadas, pentâmeras, hermafroditas 
e apresentam coloração amarela acentuada. A espécie possui flores com pistilo longo e flores com pistilo curto que são encontradas no mesmo indivíduo (a proporção de cada morfo por indivíduo não foi investigada).

Figura 2 - Indivíduos de Corchorus hirtus L. encontrados no Campus da Universidade Federal do Oeste da Bahia, Barreiras, Nordeste do Brasil. a- Habito herbáceo, inflorescências axilares e terminal com flor aberta; b- Flor mostrando pistilo longo e estames; c- flor em senescência.

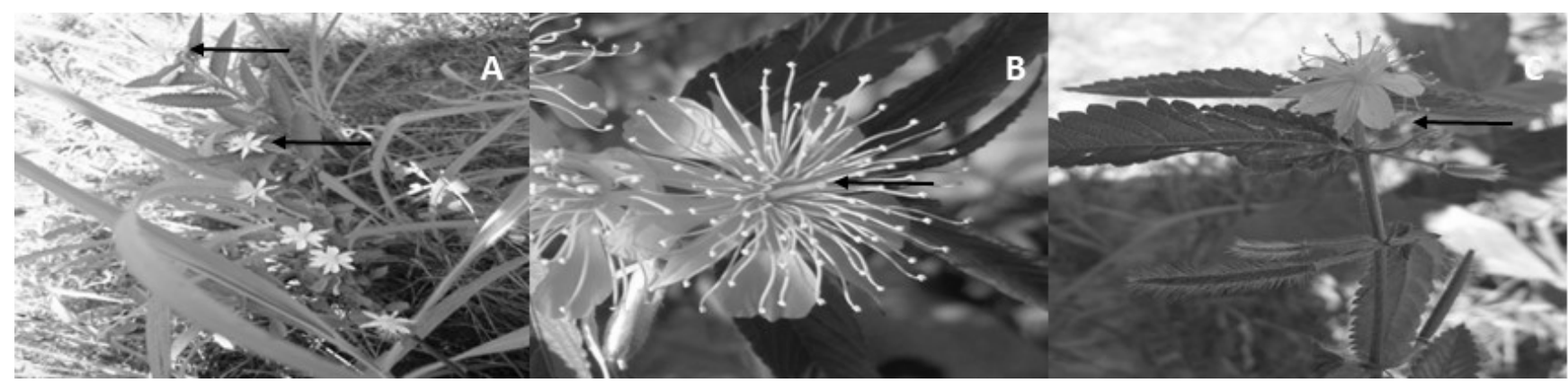

Flores de pistilo longo possuem pétalas e sépalas com maior comprimento do que flores de pistilo curto, porém ambos os verticilos são muito semelhantes em largura nos dois tipos de flores (Tabela 1). O androceu possui de 30 a 47 estames livres entre si (em ambos os morfotipos) (Figura 2b). As anteras são rimosas, longitudinais, dorsifixas medindo aproximadamente $0,1 \mathrm{~cm}$ de comprimento nos dois morfos e apresentam uma alta viabilidade polínica com média de $(98,7 \pm 0,45 \%)$ em flores de pistilo longo e $(98,4 \pm 0,47 \%)$ em flores de pistilo curto.

O gineceu é constituído por ovário súpero e quatro carpelos unidos. Houve diferença no tamanho do gineceu, estilete e do ovário entre os dois tipos de flores (Tabela 1). O fruto é do tipo cápsula, piloso, deiscente com abertura longitudinal. Quando jovem, a coloração do fruto é verde claro e quando maduro marrom. As sementes são triangulares e de coloração marrom.

Tabela 1 - Dimensões de estruturas reprodutivas e número de sementes dos dois morfotipos de Corchorus hirtus L. no Campus da Universidade Federal do Oeste da Bahia, Nordeste do Brasil; C = pistilo curto; $\mathrm{L}=$ pistilo longo.

\begin{tabular}{|c|c|c|c|c|c|c|c|}
\hline \multirow{3}{*}{ Morfotipo } & \multicolumn{4}{|c|}{ Perianto } & \multicolumn{3}{|c|}{ Pistilo } \\
\hline & Pétalas & Pétalas & Sépala & Sépala & Gineceu & Estilete & Ovário \\
\hline & comp. (mm) & larg. (mm) & comp. (mm) & larg. (mm) & $(\mathrm{mm})$ & $(\mathrm{mm})$ & $(\mathrm{mm})$ \\
\hline C & $0,65 \pm 0,14$ & $0,35 \pm 0,09$ & $0,65 \pm 0,1$ & $0,19 \pm 0,03$ & $0,58 \pm 0,12$ & $0,25 \pm 0,11$ & $0,25 \pm 0,07$ \\
\hline $\mathbf{L}$ & $0,87 \pm 0,05$ & $0,36 \pm 0,05$ & $1,06 \pm 0,14$ & $0,2 \pm 0,0$ & $1,02 \pm 0,14$ & $0,7 \pm 0,0$ & $0,38 \pm 0,1$ \\
\hline C & $0,65 b$ & $0,35 \mathrm{a}$ & $0,65 b$ & $0,19 \mathrm{a}$ & $0,58 b$ & $0,25 b$ & $0,25 b$ \\
\hline $\mathbf{L}$ & $0,87 a$ & $0,36 a$ & $1,06 \mathrm{a}$ & $0,20 \mathrm{a}$ & $1,02 a$ & $0,70 \mathrm{a}$ & $0,38 \mathrm{a}$ \\
\hline Dms & 0,09 & 0,07 & 0,11 & 0,02 & 0,12 & 0,07 & 0,08 \\
\hline CV $(\%)$ & 13,33 & 19,81 & 13,76 & 11,47 & 16,46 & 16,08 & 28,1 \\
\hline
\end{tabular}

Dados seguidos pelas mesmas letras, nas colunas, não diferem significativamente entre si ao nível de 5\% de probabilidade 
Flores de $C$. hirtus apresentam uma forte coloração amarelo acentuado em todas as peças florais. A flor dura cerca de três horas com a abertura dos botões ocorrendo entre 14:30h e 15:30h. O processo inicia-se com a abertura das sépalas e posteriormente das pétalas, levando aproximadamente 30 minutos para que se abram completamente, deixando expostos numerosos estames com grãos de pólen já disponíveis e estigma receptivo. A receptividade permaneceu durante três horas, porém, a disponibilidade polínica foi de duas horas. O processo de senescência ocorreu depois das 17:00h quando os estames começam a se juntar em direção ao centro da flor, em seguida as pétalas se elevam por completo. As sépalas foram as últimas a se fechar, elas permanecem todas abertas levando alguns minutos para se elevarem completamente. A queda das flores que não formaram frutos ocorre somente no dia seguinte. Os indivíduos apresentaram de duas a 17 flores por dia, mas nas inflorescências apenas uma flor se abria por vez, raramente duas (Figura 2c). As flores de $C$. hirtus aparentemente não emitem cheiro, mas osmóforos foram encontrados nas anteras, estigmas e ovários. Já o néctar não teve sua presença registrada.

\section{Sistema Reprodutivo}

Corchorus hirtus apresentou em tratamentos de polinização aberta (controle) uma taxa de aproximadamente $80 \%$ de frutificação em flores de pistilo longo. Nos indivíduos estudados a taxa de frutos resultantes da polinização cruzada tendo como receptores de pólen flores com pistilo longo foi de aproximadamente $20 \%$ (Tabela 2). Ocorreu formação de frutos por autopolinização manual e espontânea em flores de pistilo longo em 80\% dos tratamentos, sendo portanto, considerada uma espécie autocompatível (Tabela2). As flores de pistilo pequeno não formaram frutos em nenhum tratamento (Tabela 2).

Tabela 2 - Resultados das polinizações controladas (número de flores/número de frutos formados) em Corchorus hirtus $\mathrm{L}$. no Campus da Universidade Federal do Oeste da Bahia, Barreiras, Nordeste do Brasil. $\mathrm{L}=$ pistilos longo; $\mathrm{C}=$ pistilo curto; (doador x receptor); PC- polinização cruzada; AE- Autopolinização espontânea; AM- Autopolinização manual; PN- Polinização natural; AP- Apomixia.

\begin{tabular}{|c|c|c|c|c|c|c|c|c|c|c|c|c|}
\hline \multirow{3}{*}{$\begin{array}{c}\text { Tratamento } \\
\text { Morfo }\end{array}$} & \multicolumn{4}{|c|}{ PC } & \multicolumn{2}{|c|}{$\mathrm{AE}$} & \multicolumn{2}{|c|}{$\mathbf{A M}$} & \multicolumn{2}{|c|}{ PN } & \multicolumn{2}{|c|}{ AP } \\
\hline & \multicolumn{2}{|c|}{ Intramorfo } & \multicolumn{2}{|c|}{ Intermorfo } & \multirow[b]{2}{*}{ C } & \multirow[b]{2}{*}{$\mathbf{L}$} & \multirow[b]{2}{*}{ C } & \multirow[b]{2}{*}{$\mathbf{L}$} & \multirow[b]{2}{*}{ C } & \multirow[b]{2}{*}{$\mathbf{L}$} & \multirow[b]{2}{*}{ C } & \multirow[b]{2}{*}{$\mathbf{L}$} \\
\hline & $\mathbf{L} \times \mathbf{L}$ & $\mathrm{C} \times \mathrm{C}$ & $L \times C$ & $C \times L$ & & & & & & & & \\
\hline Flor/Fruto & $10 / 2$ & $10 / 0$ & $10 / 0$ & $10 / 2$ & $10 / 0$ & $10 / 8$ & $10 / 0$ & $10 / 8$ & $10 / 0$ & $10 / 8$ & $10 / 0$ & $10 / 0$ \\
\hline
\end{tabular}

\section{Visitantes Florais}

Os visitantes apareceram por todo o período de antese. Apenas três táxons de visitantes florais foram observados. Uma espécie da família Vespidae (Figura 3a; não identificada), a abelha Megachile (Acentron) verrucosa (Bréthes, 1909) (Figura 3b) e um agente pilhador Phibalosoma phyllinum (Gray, 1935), conhecido como "bicho pau" (Figura 3c).

Figura 3- Visitantes florais de Corchorus hirtus L. no Campus da Universidade Federal do Oeste da Bahia, Barreiras, 
Nordeste do Brasil. a- Vespidae (não identificada), b- Megachile (Acentron) verrucosa agarrando estames e estigma e cPhibalosoma phyllinum.

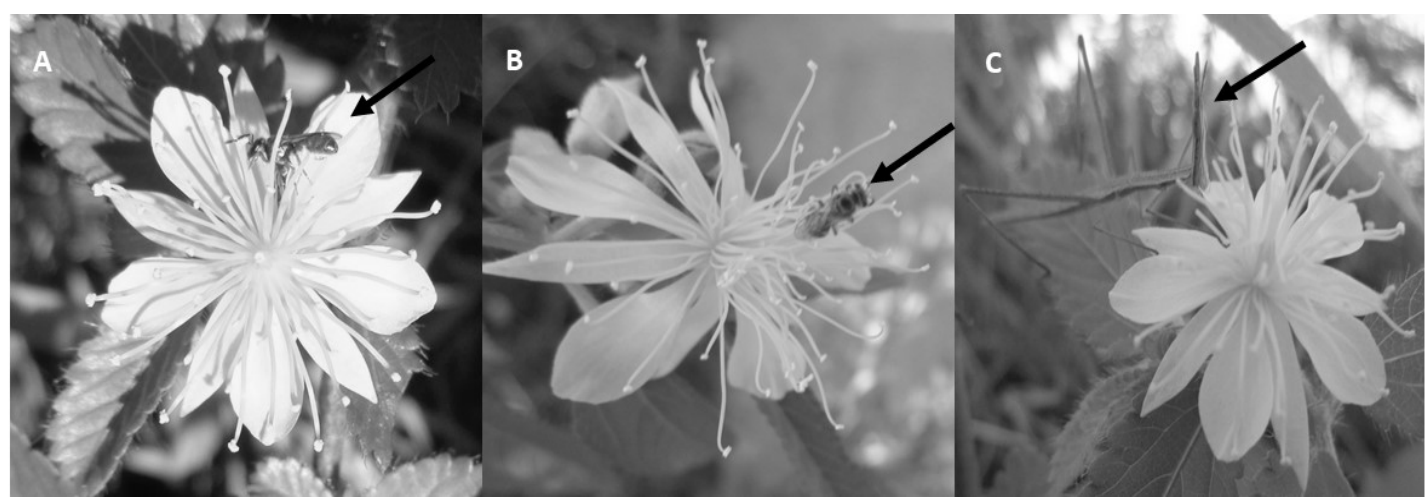

A abelha apresentou comportamento giratório em torno da flor, visitando todas as flores abertas possíveis e permanecendo em cada uma cerca de 1 minuto, tais visitas ocorriam em intervalos que variavam entre $15 \mathrm{e}$ 30 minutos. As vespas (Vespidae) por sua vez foram os visitantes mais frequentes (Tabela 3) e permaneciam na flor por um período de três a cinco minutos. Tanto a abelha quanto a vespa tocaram o estigma e a antera durante a visitação, mas não foi possível observar se houve transferência de pólen para o corpo destes insetos. O "bicho-pau" (Phibalosoma phyllinum), comportou-se como agente antagônico comendo partes florais em especial as pétalas.

Tabela 3-Visitantes florais de Corchorus hirtus L. encontrados no Campus da Universidade Federal do Oeste da Bahia, Barreiras, Nordeste do Brasil.

\begin{tabular}{lc}
\hline Visitantes florais & $\begin{array}{c}\text { Número total de visitas } \\
\text { (Frequência de visitação) }\end{array}$ \\
\hline Megachile (Acentron) verrucosa & $10(33,33 \%)$ \\
Vespidae (não determinada) & $19(63,33 \%)$ \\
Phibalosoma phyllinum & $1(3,33 \%)$ \\
Total de visitas & 30 \\
\hline
\end{tabular}

\section{Discussão}

\section{Morfometria floral}

Corchorus hirtus encontrada em um fragmento de Cerrado na região Oeste da Bahia apresentou dimorfismo floral evidente. A ausência de formação de frutos nas flores com pistilo curto indica que elas podem ser consideradas funcionalmente masculinas. Mediante o fato de que os dois morfos foram encontrados no mesmo indivíduo, sugerimos que a espécie na área estudada pode ser considerada como andromonóica. Nesse sentido, parece que em $C$. hirtus o papel reprodutivo das flores de pistilo curto ou funcionalmente estaminadas envolve a doação de pólen e atração de polinizadores, enquanto as flores de pistilo longo contribuem com genes para a próxima geração por duas vias, pólen e óvulos (Anderson e Symon 1989).

A andromonoicia é amplamente distribuída tanto em plantas polinizadas por insetos quanto naquelas polinizadas pelo vento (Lloyd 1979; Primack e Lloyd 1980; Bawa e Beach 1981; Thomson e Barrett 1981). Nas 
plantas com esse tipo de sistema sexual a produção de numerosas flores masculinas aumenta as chances de deposição de pólen no estigma das flores hermafroditas (Janzen 1977).

Em Malvaceae a andromonoicia é pouco evidenciada na literatura, um exemplo é Sterculia urens, uma espécie que produz largo número de flores masculinas e uma pequena quantidade de flores hermafroditas. No entanto Sunnichan et al. (2004) evidenciaram a esterilidade das anteras nas flores bissexuais, o que os levou a concluir que as flores bissexuais de $S$. urens são funcionalmente femininas. No gênero Chorchorus não foram encontrados registros na literatura sobre a presença de Andromonoicia, muito embora em C. birtus descrições de sua morfologia floral sugerem que o tamanho dos estiletes é variável (Souza e Esteves, 2002).

Biologia floral

$\mathrm{Na}$ área estudada $C$. birtus apresentou flores pequenas, pouco duráveis e número relativamente baixo de flores abertas diariamente por indivíduo da população, características comuns em Malvaceae pioneiras (Gottsberger 1986). Estes parâmetros podem ser considerados baixos se comparados com os de C. hirsutus nas Bahamas, que apresentou durante o estudo até 153 flores abertas por indivíduo e longevidade floral que variou entre 3 e 5 horas (Rathcke et al. 2005), permanecendo abertas quase o dobro do tempo quando comparada a $C$. birtus no presente estudo. Para Primack (1985) flores de baixa longevidade e a abertura de poucas flores por dia não favorecem a polinização cruzada.

Apesar de em Malvaceae o néctar ser um recurso secretado dentro das sépalas e alcançado através de fendas na base das pétalas (Endress 2001) a presença desse recurso não foi evidenciada em C. hirtus. A ausência de néctar não seria uma novidade para espécies do gênero Corchorus, pois já foi relatada por Rathcke et al. (2005) em C. hirsutus. Apesar disso, estudos anatômicos são necessários para averiguar de maneira segura a presença ou não de estruturas secretoras de néctar.

Na população estudada $C$. hirtus não apresentou separação temporal da maturação dos órgãos reprodutivos, estando tanto o estigma receptivo quanto o pólen disponível já no momento da abertura da flor. Isto somado ao fato da espécie ser autocompatível, criou extensa oportunidade para a ocorrência de autopolinização. Lloyd e Schoen (1992) salientam que esta situação é muito benéfica quando polinizadores e chances potencias de cruzamento são imprevisíveis no tempo e no espaço.

\section{Visitantes florais}

Na região estudada $C$. hirtus recebeu poucas visitas durante o período investigado e possui poucos visitantes florais. Apesar disso, uma espécie da família Vespidae e uma espécie de abelha (Megachile (Acentron) verrucosa) foram vistas tocando as estruturas reprodutivas durante a visitação. Muito embora em ambos os casos tenha ocorrido uma visita legítima, na qual o visitante aborda a flor entrando diretamente na unidade de polinização, tendo como principal consequência o contato com os órgãos reprodutivos (Alves-dos-Santos et al. 2016) não se pode afirmar com segurança que houve transferência de pólen para o corpo desses insetos e consequentemente do corpo para o estigma, portando faz-se necessário estudos futuros sobre a eficácia (Freitas 2013) de cada uma das espécies de visitantes e sua contribuição para a propagação de $C$. birtus no local.

Existe pouca evidência na literatura sobre visitação floral no gênero Corchorus tendo apenas C. hirsutus sido 
pesquisada sobre este aspecto. A espécie investigada em duas localidades nas Bahamas por Rathcke et al. (2005) foi visitada por diferentes grupos de visitantes, incluindo abelhas, borboletas, moscas e trips. Os principais visitantes florais da espécie foram as abelhas Megachile (Psendocentron) alleni Mitchell, 1927 (Megachilidae) e Agapostemon columbi Roberts, 1972 (Halactidae), tendo sido ambas consideradas polinizadoras efetivas. Para os autores borboletas e moscas parecem ter pousado nas flores acidentalmente, tendo em vista que são insetos que tradicionalmente forrageiam por néctar, recurso que a espécie estudada não apresentava.

Muito embora espécies da família Malvaceae possam ser polinizadas por Beija Flores e Morcegos, por exemplo. A diversificação da família e sua migração para habitats mais abertos ou até ruderais, a polinização por abelhas tornou-se mais proeminente, ocorrendo mais frequentemente nas espécies não tubulares e de hábito herbáceo (Gottsberger 1986), características que se encaixam em C. birtus.

\section{Sistema reprodutivo}

Considerando a expressiva formação de frutos de C. birtus nos tratamentos de autopolinização, se comparados aos de polinização cruzada, podemos considerar a espécie como autogâmica, podendo produzir frutos mesmo na ausência dos polinizadores que foram pouco frequentes durante o estudo. Muito embora, poucos botões tenham sido utilizados nos cruzamentos, a autogamia em espécies do gênero Corchorus é uma ocorrência comum conforme afirmaram Sinha et al. (2011), a exceção segundo estes autores é C. cunninghamii que se reproduz apenas por polinização cruzada. Adiconalmente, Rathcke et al. (2005) também apontaram ausência de autopolinização em C. hirsutus. A autopolinização é uma característica prevalente dentro das espécies mais derivadas da família Malvaceae, tornando-se uma das razões para o sucesso de muitas espécies herbáceas desse grupo (Gottsberger 1986).

Muito embora um dos efeitos da autopolinização seja a diminuição da diversidade genética que pode levar a baixa viabilidade dos descendentes, esta estratégia é viável para situações emergenciais, como em casos de baixa frequência de polinizadores, situação que parece acontecer com C. hirtus. Optando pela autopolinização as plantas garantem o sucesso reprodutivo sem desprender grande gasto energético com a produção de recursos florais para atração (Barrett 2014). Outra vantagem é que os descendentes oriundos da autopolinização são mais uniformes do que aqueles descendentes da polinização cruzada, tais progênies podem conter alta proporção de indivíduos bem adaptados a certo habitat (Raven 2002). Todavia, estudos de natureza genética são necessários para avaliar os efeitos da autopolinização na estrutura da população de C. hirtus.

Finalmente outro aspecto importante a ser considerado é que C. hirtus formou frutos nos tratamentos de autopolinização espontânea, isto significa que a espécie possui algum mecanismo que permite a polinização sem que haja a participação de um agente externo que faça o transporte mesmo que acidental do grão de pólen. De acordo com Lloyd e Schoen (1992) a autopolinização espontânea pode acontecer antes, durante ou depois das oportunidades de polinização cruzada na flor e como resultado desses diferentes tempos de acontecimento, elas também diferem no grau em que deslocam para mais ou para menos a ocorrência da polinização cruzada (Ockendon e Currah 1978).

Apesar da autopolinização tardia (aquela que ocorre após as chances de polinização cruzada tenham ocorrido) ser frequente em Malvaceae, a ausência em C. hirtus de separação temporal entre as funções masculinas e femininas desde a abertura da flor, permite chances de ocorrência de autopolinização durante a antese e não 
apenas no final desta, como ocorre em espécies como Hibiscus laevis (Klips e Snow 1997) e Kosteletzkya virginica (Ruan et al. 2004) que curvam os estiletes no final da antese a fim de que estes toquem as anteras ou áreas não reprodutivas com pólen acumulado, permitindo oportunidades tardias de autopolinização. Desta forma fazemse necessários estudos específicos que investiguem qual mecanismo de autopolinização está ocorrendo em $C$. birtus.

\section{ConClusões}

C. hirtus na área estudada apresentou-se dois morfos florais que contribuem de maneira diferenciada para o sucesso reprodutivo da espécie, onde flores de pistilo curto adotam funcionamento masculino contribuindo com a atração de polinizadores e com a doação de pólen, enquanto as flores de pistilo longo contribuem tanto com a função masculina como com a função feminina. Essas condições nos levaram a considerar a população de C. hirtus estudada como andromonóica.

A alta taxa de frutificação em diferentes tratamentos de autopolinização nos leva a considerar a população estudada como autogâmica, fato que associado a baixa frequência de visitação e baixo número de espécies visitantes nos levou a inferir que $C$. hirtus não está dependendo dos serviços dos polinizadores para reproduzirse naquele local.

Muito embora parte dos resultados encontrados necessitem de investigações mais apuradas este estudo fornece os primeiros ensaios sobre a biologia floral, os visitantes florais e o sistema reprodutivo de uma espécie pouco investigada presente em uma região sobre a qual dados sob muitos aspectos de sua biodiversidade são praticamente inexistentes, o que torna importante a divulgação desses achados.

\section{REFERÊNCIAS}

Alves-dos-Santos, Silva CI, Pinheiro M, Kleinert AMP. 2016. Quando um visitante floral é um polinizador? Rodriguésia, 67(2): 295-307. DOI: dx.doi.org/10.1590/2175-7860201667202.

Anderson GJ, Symon DE. 1989. Functional dioecy and Andromonoecy in Solanum. Evolution, 43: 204-219. DOI: $10.1111 /$ j.1558-5646.1989.tb04218.x

Batistella M, Valladares GS. 2009. Expansão agrícola e degradação da terra no Oeste da Bahia, Brasil. Biota Neotropical, 9(3): 61-76. DOI: dx.doi.org/10.1590/S1676-06032009000300005.

Barrett SCH. 2000. Advanced Plant Sex. Review of Gender \& Sexual Dimorphism in Flowering Plants. In: Geber MA, Dawson TE e Delph LF. (eds.), Trends in Ecology \& Evolution, 15: 78-79.

Barrett SCH. 2014. Evolution of mating systems: outcrossing versus selfing. In: Losos J. (ed.), The Princeton Guide to Evolution, Princeton/New Jersey: Princeton University Press, p. 356-362.

Bawa KS, Beach JH. 1981. Evolution of sexual systems in flowering plants. Annals of the Missouri Botanical Garden, 68: 254-274. DOI: 10.2307/2398798. 
Chang H, Miau R. 1989. Tiliaceae. In: Chang H (ed.), F1 Reipubl. Popularis Sin, 49:47-123.

Colmenero-Robles JÁ, Gual-Diaz M, Fernández-Nova R. 2010. El Género Cochorus (Tiliaceae) en México. Polibotânica, 29: 29-65.

Costa CBN, Costa JAS. 2010. Panorama ambiental da região oeste da Bahia: Síntese do conhecimento atual sobre a biodiversidade e perspectivas para a conservação. In: Neto JP e Santos FS. (Orgs.), Oeste da Bahia: aspectos agrícolas, ecológicos e econômicos, Salvador: EDUNEB, p. 131-162.

Cuevas CNR; Manzanares AR. 1993. Primer registro de Corchorus hirtus 1. (tiliaceae) en Cuba. Acta Botánica Mexicana, 21:23-26.

Dafni A. 1992. Pollination ecology: a pratical approach, New York: Oxford University Press, 249p.

Endress PK. 2001. Diversity and Evolutionary Biology of Tropical Flowers, Cambridge: Cambridge University Press, 511p.

Freitas L. 2013. Concepts of pollinator performance: is a simple approach necessary to achieve a standardized terminology? Brazilian Journal of Botany, 36(1): 3-8. DOI: doi.org/10.1007/s40415-013-0005-6.

Bovini MG. 2015. Corchorus in Lista de Espécies da Flora do Brasil. Jardim Botânico do Rio de Janeiro. Disponivel em: < http://floradobrasil.jbri.gov.br/jabot/floradobrasil/FB9042>

Gavilanes ML, D’ Angieri Filho Cláudio N. 1991. Flora ruderal da cidade de Lavras, MG. Acta Botanica Brasilica, 5(2): 77-88. DOI: dx.doi.org/10.1590/S0102-33061991000200005.

Gottsberger G. 1986. Some pollination strategies in Neotropical savannas and forests. Journal of Systematic and Evolution, 152: 29-45.

Guglieri-Caporal A, Caporal FJM, Pott A. 2010. Phytosociology of sown pasture weeds under two levels of degradation in brazilian savanna areas, Mato Grosso do Sul state, Brazil. Pesquisa Agropecuária Tropical, 40(30): 312-321. DOI: 10.5216/pat.v40i3.6051.

Janzen DH. 1977. A note on optimal mate selection by plants. American Naturalist, 111(978): 365- 371.

Kearns CA, Inouye DW. 1993. Techniques for pollination biologists, Niwot: University Press, 913p.

Klips RA, Snow AA. 1997. Delayed autonomous self-pollination in Hibiscus laevis (Malvaceae). American Journal of Botany, 84: 48-53. DOI: 10.2307/2445882.

Kundu BC. 1951. Origin of jute. Indian Journal of Genetics and Plant Breeding, 2: 95-99.

Lloyd DG. 1979. Parental strategies in angiosperms. New Zealand Journal of Botany, 17: 595-606. DOI: doi. org/10.1080/0028825X.1979.10432573.

Lloyd DG. 1980. Sexual strategies in plants. I. An hypothesis of serial adjustment of maternal investment during one reproductive session. New Phytologist, 86: 69-79. 
Lloyd DG, Schoen DJ. 1992. Self- and cross-fertilization in plants. I. Functional dimensions. International Journal of Plant Science, 153: 358-369. DOI: doi.org/10.1086/297040.

Mendonça JO. 2006. O potencial de crescimento da produção de grãos no Oeste da Bahia. Secretaria de Agricultura, Irrigação e Reforma Agrária. Revista Bahia Agrícola, 7: 38-46.

Mori AS, Matos Silva LA, Lisboa G, Corandin L. 1989. Manual de Manejo do Herbário Fanerogâmico, $2^{\mathrm{a}}$ ed., Ilhéus: CEPEC/CEPLAC, 104p.

Ockendon DJ, Currah L. 1978. Time of cross and self-pollination affects the amounts of self-seed set by partially self-incampatible plants of Brassica oleracea. Theoretical and Applied Genetics, 52:223-237. DOI: 10.1007/BF00273895.

Oliveira PE, Maruyama PK. 2015. Sistemas de reprodução. In: Rech, AR, Agostini K, Oliveira PE e Machado ICM (orgs). Biologia da Polinização. Rio de Janeiro: Editora Projeto Cultural/PNUMA/MMA, p. 71-94.

Peel MC, Finlayson BL, Mcmahon TA. 2007. Updated world map of the Koppen-Geiger climate classification. Hydrology And Earth System Sciences, 11: 1633-1644. DOI: doi.org/10.5194/hess-11-16332007.

Primack RB, Lloyd DG. 1980. Andromonoecy in the New Zealand montane shrub manuka, Leptospermum scoparium (Myrtaceae). American Journal of Botany, 67: 361-368. DOI: 10.2307/2442346.

Primack RB. 1985. Longevity of individual flowers. Annual Review of Ecology and Systematics, 16: 15-37.

Purseglove JW. 1968. Tropical crops - dicotyledons, vol 2., London: Longman \& Green, pp. 613-618

Raven PH, Johnson GB. 2002. Plant reproduction. In: Biology, Boston: McGraw-Hill, p. 837-852.

Rathcke BJ, Kass LB, Elliott NB. 2005. The pollination biology of Woolly Corchorus, Corchorus hirsutus (Malvaceae/ Tiliaceae) on San Salvador and Inagua, Bahamas. In: Buckner S.D. e McGrath TA (eds.), Proceedings 10th Symposium on the Natural History of the Bahamas, San Salvador Islands, The Bahamas, p 106-113.

Radford AE, Dickinson WC, Massey JR, Bell CR. 1974. Vascular Plant Systematics, New York: Harper \& Row, 891p.

Ribeiro JF, Walter BMT. 2008. As principais fitofisionomias do Cerrado. In: Sano SM et al. (eds.), Cerrado: Ecologia e flora, Brasília: EMBRAPA, p. 152-212.

Ruan CJ, Qin P, He ZX. 2004. Delayed autonomous selfing in Kosteletrkya virginica (Malvaceae) South African Journal of Botany, 70(4): 640-645. DOI: doi.org/10.1016/S0254-6299(15)30204-0.

Santos LL, Ramos MA, Silva SI, Sales MF, Albuquerque UP. 2009. Caatinga Ethnobotany: Anthropogenic Landscape Modification and Useful Species in Brazil's Semi-Arid Northeast. Economic botany, 63(363). DOI: doi.org/10.1007/s12231-009-9094-3.

Sinha MK, Kar CS, Ramasubramanian T, Kundu A, Mahapatra B.S. 2011. Corchorus. In: Kole C. (eds.), Wild 
Crop Relatives: Genomic and Breeding Resources, Berlin: Springer, p. 29-33.

Souza BM, Esteves GL. 2002. Tiliaceae. In: Wanderley MGL, Shepherd GJ, Giulietti AM, Melhem TS, Bittrich V e Kameyama C. (eds.), Flora Fanerogâmica do Estado de São Paulo, São Paulo: Instituto de Botânica, p. 331-342.

Sunnichan V, Mohan Ram H, Shivanna, K. 2004. Floral sexuality and breeding system in gum karaya tree, Sterculia urens. Plant Systematic and Evolution, 244(3-4): 201-218. DOI: doi.org/10.1007/s00606-0030095-x.

Thomson JD, Barrett SCM. 1981. Selection of outcrossing, sexual selection, and the evolution of dioecy in plants. The American Naturalist, 118: 443-449.

Vieira MF, Fonseca RS. 2014. Biologia reprodutiva em angiospermas: síndromes florais, Polinizações e sistemas reprodutivos sexuados, Viçosa, MG: Ed. UFV, 2014. 